\title{
Alterations of Glomerular Filtration Rate during Cold Exposure in Progressive Systemic Sclerosis: Measurement with Technetium-99m DTPA
}

\author{
Kunihiko YAMAUCHI and Shigeru ARIMORI
}

\begin{abstract}
We investigated the changes of the glomerular filtration rate (GFR) that occurred when the right hand was soaked in $7^{\circ} \mathrm{C}$ water. The subjects were 5 patients with progressive systemic sclerosis who did not have clinical evidence of renal involvement. The clearance rate constant of ${ }^{99} \mathrm{~m}$ Tc-DTPA, which is excreted by glomerular filtration, was measured with a cadmium telluride detector placed over the chest wall. In response to the cold exposure, the constant rose in 2 patients and remained unchanged in the remaining 3 patients. After termination of cold exposure, the constant fell in all 5 patients, suggesting renal Raynaud's phenomenon. These findings suggest that the renal vasculature in these patients has an abnormal response to cold exposure.
\end{abstract}

Key words: Renal Raynaud's phenomenon, Right hand

Diethylenetriaminepentaacetic acid (DTPA) is excreted by glomerular filtration. After equilibration of DTPA in the blood and the extravascular space, the rate constant of the monoexponential disappearance of the activity, as shown by an external detector, can provide an empirical estimate of the glomerular filtration rate (GFR) (1). External counting of technetium-99m $\left({ }^{99 \mathrm{~m}} \mathrm{Tc}\right)$-labeled DTPA with a portable cadmium telluride detector can be used for the measurement of GFR $(2,3)$. In addition, this method can continuously monitor minor changes of GFR that are induced by various experimental conditions.

Vascular lesions are present in renal tissue obtained post-mortem from normotensive patients with progressive systemic sclerosis (PSS) who die with normal renal function (4). Vascular abnormalities also are revealed in renal biopsy specimens obtained from normotensive patients with normal renal function (5). Additionally, some reports $(5,6)$ have stated that these patients are affected by renal Raynaud's phenomenon, as one of the functional abnormalities of their renal vasculature. However, continuous changes of GFR induced by exposure to cold have not previously been investigated in PSS patients. Therefore, we investigated the external clearance of ${ }^{99} \mathrm{~m}$ Tc-DTPA in PSS patients who did not have clinical evidence of renal involvement, to detect any functional abnormality of the vascular response to cold exposure in the kidneys.

\section{MATERIALS AND METHODS}

\section{Patients}

Five patients with PSS were studied, all of whom met the 1980 preliminary criteria for diagnosis of PSS published by the American Rheumatism Association (7). There were 4 females and one male, with a mean age of 54 years (range: 32-74 years). They were normotensive and had normal renal function. Normotension was defined as a blood pressure of $<140 / 90 \mathrm{mmHg}$ on multiple determinations. Normal renal function was determined by the finding of a normal urinalysis, a serum creatinine of $0.8-1.2 \mathrm{mg} / \mathrm{dl}$, a creatinine clearance $>70$

From Department of Internal Medicine, Tokai University School of Medicine, Isehara

Received for publication June 28, 1989; Accepted for publication February 27, 1990

Reprint requests should be addressed to Kunihiko Yamauchi, MD, Department of Internal Medicine,

Tokai University School of Medicine, Bohseidai, Isehara 259-11, Japan 
Table 1. Clinical findings.

\begin{tabular}{|c|c|c|c|c|c|c|c|c|}
\hline \multirow{2}{*}{$\frac{\text { Case }}{1}$} & \multirow{2}{*}{$\frac{\text { Age/Sex }}{74 / \mathrm{F}}$} & \multirow{2}{*}{$\frac{\begin{array}{c}\text { Duration of PSS } \\
\text { (month) }\end{array}}{48}$} & \multirow{2}{*}{$\frac{\text { Blood pressure }}{\text { Normal }}$} & \multirow{2}{*}{$\frac{\begin{array}{l}\text { PRA } \\
(\mathrm{ng} / \mathrm{ml} / \mathrm{h})\end{array}}{0.2}$} & \multirow{2}{*}{$\begin{array}{c}\begin{array}{c}\mathrm{s}-\text { Creatinine } \\
(\mathrm{mg} / \mathrm{dl})\end{array} \\
1.0\end{array}$} & \multicolumn{3}{|c|}{$\begin{array}{l}\text { Urinalysis } \\
\text { protein/RBC/cast }\end{array}$} \\
\hline & & & & & & $\mathrm{N}$ & $/ \mathrm{N}$ & $/ N$ \\
\hline 2 & $32 / \mathrm{F}$ & 140 & Normal & 1.7 & 0.8 & $\mathrm{~N}$ & $/ \mathrm{N}$ & $/ \mathrm{N}$ \\
\hline 3 & $59 / \mathrm{F}$ & 158 & Normal & 0.5 & 0.9 & $\mathrm{~N}$ & $/ \mathrm{N}$ & $/ \mathrm{N}$ \\
\hline 4 & $45 / F$ & 49 & Normal & 1.7 & 0.8 & $\mathrm{~N}$ & $/ \mathrm{N}$ & $/ \mathrm{N}$ \\
\hline 5 & $59 / \mathrm{M}$ & 77 & Normal & 1.8 & 1.0 & $\mathrm{~N}$ & / $\mathrm{N}$ & $/ \mathrm{N}$ \\
\hline
\end{tabular}

PRA: plasma renin activity, $\mathrm{N}$ : negative, RBC: red blood cell

$\mathrm{ml} / \mathrm{min}$, and a plasma renin activity (PRA) of $0.3-2.9 \mathrm{ng} / \mathrm{ml} / \mathrm{h}$. Digital Raynaud's phenomenon in these patients had developed at approximately the same time as the onset of PSS. Two patients (cases 1 and 3) did not take any dose of prednisolone until the investigation, but the remaining 3 patients (cases 2, 4 and 5) were taking 5 or $10 \mathrm{mg}$ of prednisolone daily for 9, 4 and 6 years, respectively. All patients were taking $\mathrm{dl}-\alpha$-tocopherol nicotinate (: microcirculation activator) and/or elastase (: vasometabolism activator). Vasodilator was not administered to these patients. They were all non-smokers. None of the patients had edema. Table 1 lists the clinical findings from the study group. Four control subjects with normal renal function were also studied, who were females with a mean age of 50 years (range, 29 to 64 years). The patients and control subjects were fully informed of the objectives of the study and gave consent.

\section{Estimation of GFR with ${ }^{99 m} T c-D T P A$}

The studies were performed under standardized conditions with the subjects in the supine position. ${ }^{99 m}$ Tc-DTPA was prepared from a kit (Daiichi Radioisotope Labs. Ltd.) using ${ }^{99 m} \mathrm{Tc}$ as pertechnetate to give an activity of $370 \mathrm{MBq}(1 \mathrm{mCi})$ in $1 \mathrm{ml}$. A dose of $740 \mathrm{MBq}(2 \mathrm{mCi})$ of ${ }^{99 \mathrm{~m}} \mathrm{Tc}$ DTPA was injected intravenously as a single bolus, after which the syringe was again flushed. A CdTe detector (Aloka Co. Ltd.) was placed on the right side of the sternum immediately below the right clavicle. Recordings were made at 12 -second intervals from 0 to 180 minutes after injection of the chelate using an LSI-11/23 microcomputer (DEC Japan Ltd.). Cold exposure consisted of soaking the right hand in $7^{\circ} \mathrm{C}$ water for periods of from 120 to 140 minutes. Clearance rate constants were calculated for the time periods of 90 to 120 minutes, 120 to 140 minutes, and 140 to 170 minutes, which represented the periods before, during, and after the cold exposure, respectively. Comparison was made between the constants in the same patient.

\section{RESULTS}

The chest curve disappearance constants produced by cold exposure to the right hand are shown in Fig. 1. The constant rose in 2 of 5 patients in response to the cold exposure as compared with the level before exposure, but it remained unaltered in the remaining 3 patients. After termination of the cold exposure, the mean value was $0.59 \% / \mathrm{min}$, which was a significant fall in comparison to the values of $0.75 \% / \mathrm{min}$ or $0.80 \% / \mathrm{min}$ recorded before and during cold exposure, respectively. The results suggested the existence of renal Raynaud's phenomenon as a late response to cold exposure. The records for case 3, in whom the constant rose during cold exposure and fell after the removal, are

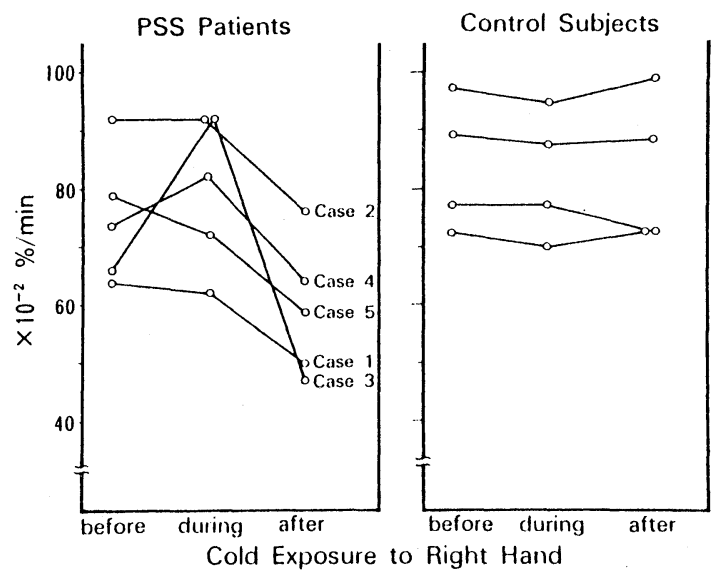

Fig. 1. Clearance rate constants of ${ }^{99 \mathrm{~m}} \mathrm{Tc}$-DTPA over chest wall before, during and after the cold exposure in 5 patients with PSS and 4 control subjects. 


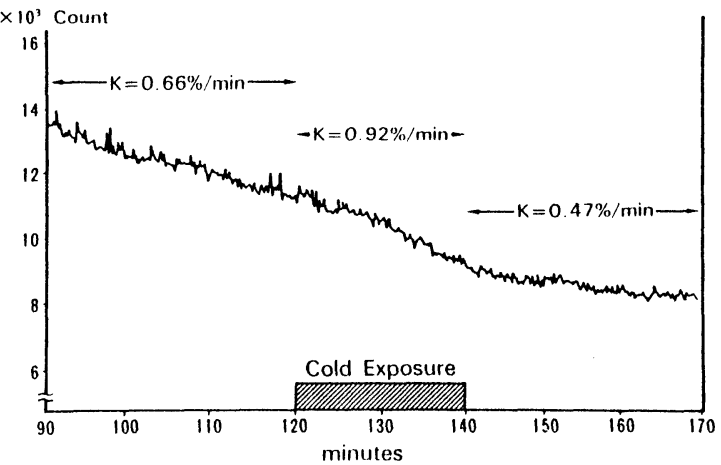

Fig. 2. Externally recorded curve of ${ }^{99 m}$ Tc-DTPA activity during rest and cold exposure to right hand in case 3. The values of clearance rate constants $(\mathrm{K})$ measured before, during and after the cold exposure are shown.

shown in Fig. 2. The mean follow-up interval after the clinical onset of PSS was 95 months, with a range of 47 to 160 months. Throughout the followup period, proteinuria, hypertension or an increase of serum creatinine has not developed in any of these patients.

\section{DISCUSSION}

The plasma kinetics of ${ }^{99 \mathrm{~m}}$ Tc-DTPA can be described by an open two-compartment mammillary model, in which the activity is constantly mixing between the vascular and extravascular spaces and being cleared into the urine. Once complete mixing has taken place within the body, these two pools effectively become one and plasma disappearance then reflects the GFR. Investigators $(8,9)$ have demonstrated that it is possible to determine ${ }^{99 \mathrm{~m}} \mathrm{Tc}$ DTPA clearance by the combination of blood sampling and external monitoring of the timeactivity curve. The determination of clearance has been further simplified. Groth and co-workers (2) have reported not only that the final slope of the plasma activity curve correlates closely to the final slope of the time-activity curve derived externally, but also that it is possible to define the final slope approximately 40 minutes after injection in patients with a GFR close to normal. It was more recently reported that the plasma clearance rate constant is approximately linear for half-time values of ${ }^{99 \mathrm{~m}} \mathrm{Tc}$ DTPA from 90 to 175 minutes in patients with clearance rates of 60 to $100 \mathrm{ml} / \mathrm{min}$ (10). The minimum error depends on GFR, a longer time being required when the GFR is low (11). Fleming and co-workers (3) showed that the GFR and the chest site clearance curve correlated well, with the standard error being $0.062 \% / \mathrm{min}$. Therefore, the error was tolerable in these patients with a GFR close to the normal range, and the changes of GFR induced by cold exposure can be considered significant. When the body surface area, the distribution space of the radiotracer, and the instrumental conditions for measuring radioactivity remain constant before, during and after cold exposure as in these subjects, the method can be used to reveal continuous changes in GFR. No other method can estimate alterations of GFR with such accuracy and such little burden to the subject.

The changes observed in the clearance constant with cold exposure suggested the presence of an abnormality in the regulation of renal blood flow in these patients without any clinical or laboratory evidence of renal disease. Although many studies have reported on vascular and glomerular lesions in PSS patients with these conditions, only a few previous reports $(5,6)$ have been presented on functional abnormalities of the renal vasculature. These observations gave rise to the concept of renal Raynaud's phenomenon in PSS patients. The ${ }^{133} \mathrm{Xe}$ washout technique has shown that exposure of the hands to cold causes a substantial reduction in outer cortical blood flow due to contraction of the renal arterioles (6). Kovalchik and co-workers (5) have showed that elevation of PRA following the placing of an ice pack on the neck may indicate the presence of renal Raynaud's phenomenon, which may be a preclinical state of renal vascular involvement. The same report (5) also revealed that PSS patients with normal PRA levels before cold exposure had either no or mild renal vascular changes, and PRA remained unaltered during cold exposure. However, patients with an elevation of PRA had prominent vascular structural abnormalities and a rise of PRA during cold exposure. All 5 patients with normal PRA levels presented here did not develop a decrease of GFR during cold exposure, but GFR decreased and remained low for a long time after the exposure. This suggested renal Raynaud's phenomenon developing as a late response to the exposure. It was also shown that GFR can increase during cold exposure as was the case in 2 of these 5 patients. None 
of our patients with normal PRA levels developed proteinuria, hypertension or renal failure during the follow-up period of 47 to 160 months. It may be postulated that patients in whom renal vasospasm is induced during cold exposure may eventually develop clinical renal involvement such as proteinuria or hypertension even if it is not yet apparent, while the patients in whom renal vasospasm is induced after cold exposure remain free of clinical renal involvement over the long term. These normotensive patients with normal renal function (renal biopsies have not been performed) may have such lesions as intimal proliferation and fibrinoid necrosis in renal vasculature. The vascular lesions may induce secondarily a physiological abnormality of vasomotor nerves that results in alterations of GFR by cold exposure. In the progressive stage of the vascular lesions, smooth muscle fibers of the vasculature may be impaired, resulting in no response to cold exposure. Our study showed that the decrease of renal blood flow resulting from vasospasm continued even for as long as 30 minutes after ending exposure to cold in PSS patients without clinical renal disease.

ACKNOWLEDGEMENTS: We are grateful to Dr. Yutaka Suzuki of the Department of Radiology for his technical assistance and scientific advice.

\section{REFERENCES}

1) Klopper JF, Hauser W, Atkins HL, et al. Evaluation of ${ }^{99 \mathrm{~m}}$ Tc-DTPA for the measurement of glomerular filtration rate. J Nucl Med 13: 107, 1972.
2) Groth $\mathrm{S}$, Christensen $\mathrm{AB}$, Nielsen $\mathrm{H}$. CdTe-detector registration of ${ }^{99 \mathrm{~m}} \mathrm{Tc}$-DTPA clearance. An assessment of kidney function without blood sampling. Eur J Nucl Med 8: 242, 1983.

3) Fleming JS, Ramsay B, Waller DG, et al. Measurement of glomerular filtration rate with a portable cadmium telluride detector. Nucl Med Comm 8: 751, 1987.

4) D'Angelo WA, Fries JF, Masi AT, et al. Pathologic observations in systemic sclerosis (scleroderma). A study of fifty-eight autopsy cases and fifty-eight matched controls. Am J Med 46: 428, 1969.

5) Kovalchik MT, Guggenheim SJ, Silverman MH, et al. The kidney in progressive systemic sclerosis. A prospective study. Ann Intern Med 89: 881, 1978.

6) Cannon PJ, Hassar M, Case DB, et al. The relationship of hypertension and renal failure in scleroderma (progressive systemic sclerosis) to structural and functional abnormalities of the renal cortical circulation. Medicine 53: 1, 1974.

7) Subcommittee for Scleroderma Criteria of the American Rheumatism Association Diagnostic and Therapeutic Criteria Committee. Preliminary criteria for the classification of systemic sclerosis (Scleroderma). Arthritis Rheum 23: 581, 1980.

8) Rossing N, Bojsen J, Frederiksen PL. The glomerular filtration rate determined with ${ }^{99 m}$ Tc-DTPA and a portable cadmium telluride detector. Scand J Clin Lab Invest 38: 23, 1978.

9). Dakubu S, Adu D, Nkrumah KN, et al. Single blood sample estimation of glomerular filtration rate. Nucl Med Comm 1: 83, 1980.

10) Fawdry RM, Gruenewald SM. Three-hour volume of distribution method: An accurate simplified method of glomerular filtration rate measurement. J Nucl Med 28; $510,1987$.

11) LaFrance ND, Drew HH, Walser M. Radioisotopic measurement of glomerular filtration rate in severe chronic renal failure. J Nucl Med 29: 1927, 1988. 